\title{
Efficacy of infliximab in the treatment of Kawasaki disease: A systematic review and meta-analysis
}

\author{
ZHONGXING LU ${ }^{1 *}$, FEN WANG ${ }^{2 *}$ and HAITAO $\mathrm{LV}^{3}$ \\ ${ }^{1}$ Department of Pediatrics, Changzhou Maternal and Child Health Care Hospital, Changzhou, Jiangsu 213023; \\ ${ }^{2}$ Department of Pediatrics, Taicang First People's Hospital; ${ }^{3}$ Department of Pediatrics, \\ Soochow Children's Hospital, Suzhou, Jiangsu 215000, P.R. China
}

Received July 25, 2019; Accepted February 20, 2020

DOI: $10.3892 /$ etm.2020.9447

\begin{abstract}
The present study aimed to review the relevant studies in order to determine the efficacy of infliximab (IFX) in the treatment of Kawasaki disease (KD). The relevant studies were retrieved using the PubMed, Cochrane and Embase databases. Key sources in the literature were reviewed; all articles published by July 2019 were considered for inclusion. For each study, odds ratios, mean difference and $95 \%$ confidence interval $(95 \% \mathrm{CI})$ were assessed to evaluate study outcomes. A total of 16 studies involving 429 patients were relevant to the questions of interest of the current meta-analysis. Compared with intravenous immunoglobulin (IVIG), IFX or IFX plus IVIG significantly reduced the incidence of adverse events, including the number of patients with fever, changes in lip and oral cavity and/or cervical lymphadenopathy. The white blood cell (WBC), neutrophil and C-reactive protein (CRP) levels were also reduced in the IFX or IFX plus IVIG group compared with those in the IVIG or polyethylene glycol-treated human immunoglobulin (VGIH) groups. The platelet counts, alanine aminotransferase (ALT) levels and Z-scores were increased in the IFX or IFX plus IVIG groups compared with those in the IVIG or VGIH groups. In the single-arm studies, the incidence
\end{abstract}

Correspondence to: Dr Haitao Lv, Department of Pediatrics, Soochow Children's Hospital, 92 Zhongnan Street, Industrial Park, Suzhou, Jiangsu 215000, P.R. China

E-mail: lvhait_htlv@163.com

*Contributed equally

Abbreviations: IFX, infliximab; KD, Kawasaki disease; OR, odds ratios; MD, mean difference; CI, confidence interval; MCLS, mucosal lymph node syndrome; CAL, coronary artery damage; VGIH, polyethylene glycol-treated human immunoglobulin; IVIG, intravenous immunoglobulin; CAL, coronary artery lesion; CAD, coronary artery disease; CAA, coronary artery aneurysm; WBC, white blood cell; AST, aspartate aminotransferase; ALT, alanine transaminase; CRP, C-reactive protein; IVMP, intravenous methyl prednisolone; WMD, weighted mean difference

Key words: infliximab, Kawasaki disease, meta-analysis of coronary artery aneurysm was 0.150 (95\% CI: 0.024, 0.277), the non-response rate was 0.097 (95\% CI: 0.056, 0.138), and the incidence of adverse events was 0.156 (95\% CI: 0.122 , 0.190). IFX not only effectively reduced the incidence of fever, conjunctival injection, changes in lip and oral cavity and cervical lymphadenopathy polymorphous exanthema, but also the WBC, neutrophil, ALT and CRP levels. The platelet levels were increased in patients after the IFX therapy compared with patients in the IVIG or VGIH groups. IFX or IFX plus IVIG exhibited improved clinical efficacy in the treatment of KD compared with that of IVIG or VGIH. However, as a limited number of studies was included in the current study, the findings should be verified further.

\section{Introduction}

Kawasaki disease (KD), alternatively known as cutaneous mucosal lymph node syndrome (MCLS), is a self-limited systemic immune vasculitis (1). A total of 20-25\% of untreated children with KD develop coronary artery damage (CAL), which has become a major cause of acquired heart disease in children (2). Currently, the exact cause of the disease remains unknown. In terms of treatment, the use of intravenous immunoglobulin (IVIG) in the acute phase can reduce the incidence of CAL to 2-4\%, and, to some extent, restore CAL (3). CAL is the most serious complication of $\mathrm{KD}$, mainly including coronary artery disease (CAD) and coronary artery aneurysm (CAA) (2,4-6). KD is characterized by endothelial function damage, coagulation and vascular morphology abnormality at the early stage; injecting IVIG in the acute phase can improve endothelial function and reduce CAD. A single dose of $2 \mathrm{~g} / \mathrm{kg}$ per day IVIG combined with aspirin has been used as the standard treatment of KD in the USA and Japan (7). However, $10-20 \%$ of children exhibit IVIG resistance, presenting a high risk of developing CAL (8). After initial treatment failure, $3-4 \%$ of children with KD need to receive further IVIG treatment, but still exhibit a limited response. Infliximab (IFX) is a monoclonal antibody that specifically blocks tumor necrosis factor (TNF)- $\alpha$, which is an important pro-inflammatory factor significantly elevated in the blood circulation of children with KD. The effectiveness of IFX in combination with IVIG treatment of non-reactive type KD is controversial; studies have reported that IFX combined with IVIG therapy does not 
reduce IVIG resistance, but IFX is effective in treating KD (9). In addition, IFX is safe and tolerable for children with KD who are resistant to IVIG $(2,10-14)$.

The aim of the present study was to perform a meta-analysis of the available literature to obtain updated evidence about the efficacy of IFX in the treatment of KD.

\section{Materials and methods}

Search strategy. To identify studies conducted on the efficacy of IFX in the treatment of KD, relevant articles published before July 2019 in the Cochrane (https://www.cochranelibrary.com/), Pubmed (https://pubmed.ncbi.nlm.nih.gov/) and Embase (https://www.embase.com/) databases were reviewed. The references of all identified articles were also reviewed to identify additional studies. The search terms were as follows: 'Infliximab', 'IFX', 'Kawasaki disease', 'KD' and 'Kawasaki'. These terms were used in combination with 'and' or 'or'. The literature review was performed independently by two researchers, with a third researcher resolving any disputes when needed.

Following the Participants, Interventions, Comparisons, Outcomes and Study design principle (15), the key criteria included: Participants, patients with KD; interventions, the patients of the single-arm study were treated by IFX, in the case-control study, patients in the experiment group were treated by IFX or IFX combined with intravenous immunoglobulin (IVIG), patients in the control group were treated by placebo or IVIG or polyethylene glycol-treated human immunoglobulin (VGIH); comparisons and outcomes, compared IFX with IVIG/VGIH in the treatment of KD and the outcomes included clinical efficacy indexes; and study design, case-control study or single-arm study.

Study selection criteria. Studies included in the current meta-analysis met the following criteria: i) Case-control study or single-arm study; ii) the inventions of the treatment group and single-arm study were IFX or IFX combined with IVIG, and the control group were treated by placebo or IVIG or VGIH; iii) the research subjects were patients with KD; and iv) studies published in English or Chinese.

Studies were excluded if they met the following criteria: i) Repeat articles or results; ii) clear data errors; iii) case reports case-control studies, theoretical research, conference reports, systematic reviews, meta-analyses, or other forms of research or comment that were not designed in a randomized controlled manner; and iv) studies without clinical outcomes.

Two researchers independently determined whether studies met the inclusion criteria, with a third resolving any disputes when needed.

Data extraction and quality assessment. For each included study, two categories of information (basic information and primary study outcomes) were extracted. Basic information relevant to the present meta-analysis was as follows: Author names, year of publication, sample size, mean age, sex and intervention. Primary clinical outcomes were as follows: CAL, CAA, non-response rate, length of hospital stay, adverse events, fever, conjunctival injection, changes in lip and oral cavity, cervical lymphadenopathy, polymorphous exanthema, combined coronary artery Z-score, white blood cell (WBC), neutrophil, platelet, aspartate aminotransferase (AST), alanine transaminase (ALT), and C-reactive protein (CRP) levels. The data extraction was performed independently by two researchers, with a third resolving any disputes when needed.

Statistical analysis. STATA v10.0 (StataCorp LP) was used for the data analysis. Heterogeneity in study results was assessed by the $\chi^{2}$ and $\mathrm{I}^{2}$ tests, and the appropriate analytical models (fixed-effect or random-effect) were determined. A $\chi^{2} \mathrm{P} \leq 0.05$ and an $\mathrm{I}^{2}>50 \%$ indicated high heterogeneity, and a random-effects model was used, whereas a $\chi^{2} \mathrm{P}>0.05$ and an $\mathrm{I}^{2} \leq 50 \%$ indicated acceptable heterogeneity, and a fixed-effects model was used. Continuous variables are reported as the mean \pm standard deviation and compared by the mean difference (MD). Categorical data are reported as percentages and compared based on relative risk (RR)/odds ratios (ORs). MD and 95\% confidence intervals (95\% CIs) were used to analyze the levels of WBC, neutrophils, platelets, AST, ALT, CRP and Z-scores. Other values were analyzed by RR and $95 \%$ CI.

\section{Results}

Overview of the included studies. A total of 514 articles were identified by the initial keyword search, but 443 of them were excluded following title and abstract review. The remaining 71 articles were subjected to a complete full-text assessment, and 55 articles were excluded for failing to meet study inclusion criteria. The reasons for exclusion were: i) Theoretical research $(n=26)$; ii) no clinical outcomes $(n=15)$; iii) repeated articles $(\mathrm{n}=3)$; and iv) case reports $(\mathrm{n}=11)$. Ultimately, a total of 16 studies $(4,13,16-29)$ incorporating 429 patients met the inclusion criteria for the current meta-analysis. The study selection is outlined in Fig. 1.

Table I summarizes the basic information of each study, including author names, year of publication, sample size, mean age, sex and intervention. According to the study design and interventions, the 16 studies were divided into groups for the subgroup analysis: i) IFX or IFX plus IVIG vs. IVIG or VGIH group (IFX vs. IVIG or VGIH; IFX plus IVIG vs. IVIG or VGIH); and ii) single-arm study (IFX, IFX plus IVIG or IVMP (intravenous methyl prednisolone).

IFX or IFX plus IVIG vs. IVIG or VGIH group. A total of nine studies containing 170 patients in the IFX or IFX plus IVIG group and 144 patients in the IVIG or VGIH group were included. No significant differences were observed in CAL (RR: 0.410; 95\% CI: 0.124, 1.353), CAA (RR: 0.687; 95\% CI: $0.286,1.652$ ), non-response rate (RR: 0.466 ; 95\% CI: $0.165,1.315$ ), length of hospital stay (weighted mean difference, WMD): -1.135 ; 95\% CI: $-2.436,-0.167)$, conjunctival injection (RR: 1.054 ; $95 \%$ CI: $0.765,1.452$ ) or polymorphous exanthema (RR: 1.040; 95\% CI: 0.664, 1.629) between the two groups. However, the incidence of adverse events (RR: 0.811; 95\% CI: 0.674, 0.977), and the WBC (WMD: -0.060 ; 95\% CI: $-0.07,-0.049$ ), neutrophil (WMD: -1.160 ; 95\% CI: $-1.171,-1.149$ ) and CRP (WMD: -3.00 ; 95\% CI: -3.017 , -2.983 ) levels were significantly reduced in the IFX or IFX plus IVIG group compared with those in the IVIG or VGIH group. 
Table I. Basic characteristics of included studies.

A, IFX or IFX plus IVIG vs. IVIG or VGIH groups

\begin{tabular}{|c|c|c|c|c|c|c|c|c|c|}
\hline \multirow[b]{2}{*}{ Author, year $(4,13,16-29)$} & \multicolumn{2}{|c|}{ Sample } & \multicolumn{2}{|c|}{$\begin{array}{c}\text { Age } \\
(\text { mean })\end{array}$} & \multicolumn{2}{|c|}{ Sex } & \multicolumn{2}{|l|}{ Intervention } & \multirow[b]{2}{*}{ (Refs.) } \\
\hline & $\mathrm{T}$ & $\mathrm{C}$ & $\mathrm{T}$ & $\mathrm{C}$ & $\mathrm{T}$ & $\mathrm{C}$ & $\mathrm{T}$ & $\mathrm{C}$ & \\
\hline Dionne et al, 2019 & 58 & 33 & 1.1 & 2 & $44 \mathrm{M}$ & $19 \mathrm{M}$ & $\begin{array}{l}\text { Infliximab } 5 \mathrm{mg} / \mathrm{kg} \text { or } \\
10 \mathrm{mg} / \mathrm{kg} \text {, and IVIG } 2 \mathrm{~g} / \mathrm{kg}\end{array}$ & IVIG, 2 g/kg & $(25)$ \\
\hline Han and Zhao et al, 2018 & 77 & 77 & 2.1 & 2.3 & $34 \mathrm{M}$ & $28 \mathrm{M}$ & $\begin{array}{l}\text { Infliximab } 5 \mathrm{mg} / \mathrm{kg} \text {, and } \\
\text { IVIG } 1 \mathrm{~g} / \mathrm{kg}\end{array}$ & IVIG, $1 \mathrm{~g} / \mathrm{kg}$ & $(27)$ \\
\hline Jone et al, 2018 & 35 & 34 & 2.1 & 3.5 & $26 \mathrm{M}$ & $28 \mathrm{M}$ & $\begin{array}{l}\text { Infliximab } 5 \mathrm{mg} / \mathrm{kg} \text { and } \\
\text { IVIG } 2 \mathrm{~g} / \mathrm{kg}\end{array}$ & IVIG, 2 g/kg & (17) \\
\hline Mori et al, 2018 & 16 & 15 & 2.5 & 3 & $10 \mathrm{M}$ & $11 \mathrm{M}$ & Infliximab $5 \mathrm{mg} / \mathrm{kg}$ & VGIH, $2 \mathrm{~g} / \mathrm{kg}$ & (18) \\
\hline Youn et al, 2016 & 11 & 32 & - & - & - & - & Infliximab $5 \mathrm{mg} / \mathrm{kg}$ & IVIG $2 \mathrm{~g} / \mathrm{kg}$ & (23) \\
\hline Tremoulet et al, 2014 & 98 & 98 & 3 & 2.8 & $60 \mathrm{M}$ & $61 \mathrm{M}$ & Infliximab $5 \mathrm{mg} / \mathrm{kg}$ & Placebo & (22) \\
\hline Son et al, 2011 & 20 & 86 & 23 & 29 & $14 \mathrm{M}$ & $55 \mathrm{M}$ & Infliximab 5 mg/kg & IVIG $2 \mathrm{~g} / \mathrm{kg}$ & $(20)$ \\
\hline Hirono et al, $2009^{\mathrm{a}}$ & 11 & 18 & 4 & 2.6 & $6 \mathrm{M}$ & $9 \mathrm{M}$ & Infliximab 5 mg/kg & IVIG $2 \mathrm{~g} / \mathrm{kg}$ & (16) \\
\hline Hirono et al, 2009 & 11 & 14 & 4 & 2.8 & $6 \mathrm{M}$ & $10 \mathrm{M}$ & Infliximab $5 \mathrm{mg} / \mathrm{kg}$ & IVIG $2 \mathrm{~g} / \mathrm{kg}$ & (16) \\
\hline Zhang et al, 2018 & 22 & 66 & 2.5 & 2.8 & $14 \mathrm{M}$ & $45 \mathrm{M}$ & Infliximab $5 \mathrm{mg} / \mathrm{kg}$ & IVIG $2 \mathrm{~g} / \mathrm{kg}$ & (19) \\
\hline
\end{tabular}

B, Single-arm study

\begin{tabular}{|c|c|c|c|c|c|}
\hline Authors, year & Sample size & Mean age & Sex & Intervention & (Refs.) $(4,13,21,24,26,30,29)$ \\
\hline Hur et al, 2019a & 27 & 41.49 & $19 \mathrm{M}$ & IVIG $\rightarrow$ IVIG $\rightarrow$ infliximab & $(24)$ \\
\hline Hur et al, 2019 & 15 & 36.53 & $10 \mathrm{M}$ & IVIG $\rightarrow$ infliximab & (24) \\
\hline Hur et al, $2019^{c}$ & 47 & 27.11 & $33 \mathrm{M}$ & IVIG $\rightarrow$ IVIG $\rightarrow$ IVMP $\rightarrow$ infliximab & (24) \\
\hline Hur et al, 2019d & 11 & 30.27 & $8 \mathrm{M}$ & IVIG $\rightarrow$ IVIG + IVMP $\rightarrow$ infliximab & (24) \\
\hline Hur et al, $2019^{\mathrm{e}}$ & 2 & 43 & $2 \mathrm{M}$ & IVIG $\rightarrow$ IVMP $\rightarrow$ infliximab & (24) \\
\hline Koizumi et al, 2018 & 13 & - & - & Infliximab $5 \mathrm{mg} / \mathrm{kg}$ & (4) \\
\hline Masuda et al, 2018 & 443 & 33 & $284 \mathrm{M}$ & Infliximab $5 \mathrm{mg} / \mathrm{kg}$ & $(28)$ \\
\hline Ogihara et al, 2014 ${ }^{\mathrm{a}}$ & 8 & 4.5 & $5 \mathrm{M}$ & Infliximab & (13) \\
\hline Ogihara et al, $2014^{\mathrm{b}}$ & 9 & 4.2 & $6 \mathrm{M}$ & Infliximab & (13) \\
\hline Sonoda et al, 2014 & 76 & 3.4 & $51 \mathrm{M}$ & Infliximab 5 mg/kg & $(21)$ \\
\hline Mori et al, 2012 & 20 & 4.6 & $10 \mathrm{M}$ & Infliximab $5 \mathrm{mg} / \mathrm{kg}$ & (26) \\
\hline Song et al, 2010 & 16 & 41.49 & $19 \mathrm{M}$ & Infliximab $5 \mathrm{mg} / \mathrm{kg}$ & (29) \\
\hline
\end{tabular}

IFX, infliximab; IVIG, intravenous immunoglobulin; VGIH, polyethylene glycol-treated human immunoglobulin; IVMP, intravenous methyl prednisolone; M, male. -: no information in the manuscript; a, b, c, d, e: different intervention analysis in the same article.

The platelet count (WMD: 10.040; 95\% CI: 9.803, 10.277), ALT level (WMD: 1.200; 95\% CI: 1.162, 1.238) and Z-score (WMD: $0.165 ; 95 \% \mathrm{CI}: 0.038,0.292$ ) were increased in the IFX or IFX plus IVIG group compared with those in the IVIG or VGIH group. The number of patients with fever (RR: 1.706; 95\% CI: 1.287, 2.261), changes in lip and oral cavity (RR: 1.452; 95\% CI: 1.043, 2.021) or cervical lymphadenopathy (RR: 1.586; 95\% CI: 1.128, 2.23) was reduced in the IFX or IFX plus IVIG group compared with those in the IVIG or VGIH group.

In the subgroup analysis, no significant differences were observed between length of hospital stay, the incidence of CAL, CAA, non-response rate or adverse events between the IFX and the IVIG or VGIH groups. The WBC, neutrophil and CRP levels were significantly reduced in the IFX group compared with those in the IVIG or VGIH groups. In addition, the platelet and ALT levels were increased in the IFX group compared with those in the IVIG or VGIH groups. No significant differences were observed in CAA, adverse events, conjunctival injection or polymorphous exanthema between the IFX plus IVIG group and the IVIG or VGIH groups. The incidence of non-response rate and length of hospital stay were all significantly reduced in the IFX plus IVIG group compared with the IVIG or VGIH groups. However, the incidence of fever, changes in lip and oral cavity and cervical lymphadenopathy were noticeably increased in the IFX plus IVIG group compared with the IVIG or VGIH groups. The Z-score was also significantly increased in the IFX plus IVIG group 


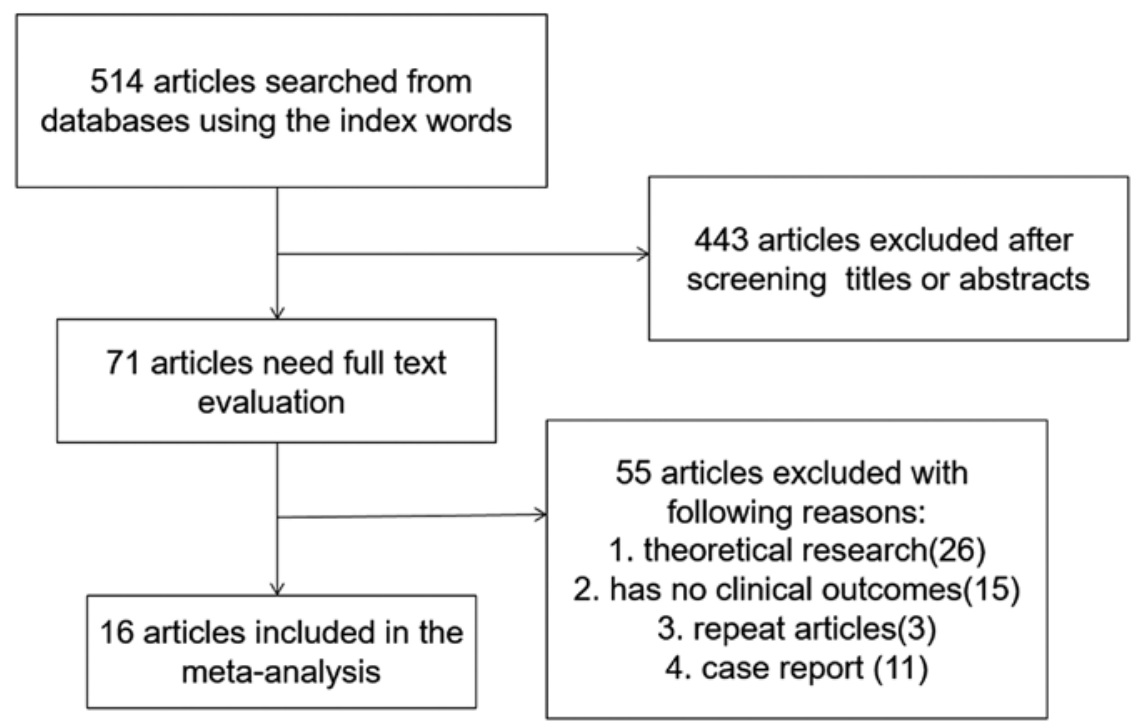

Figure 1. Literature search and selection strategy.

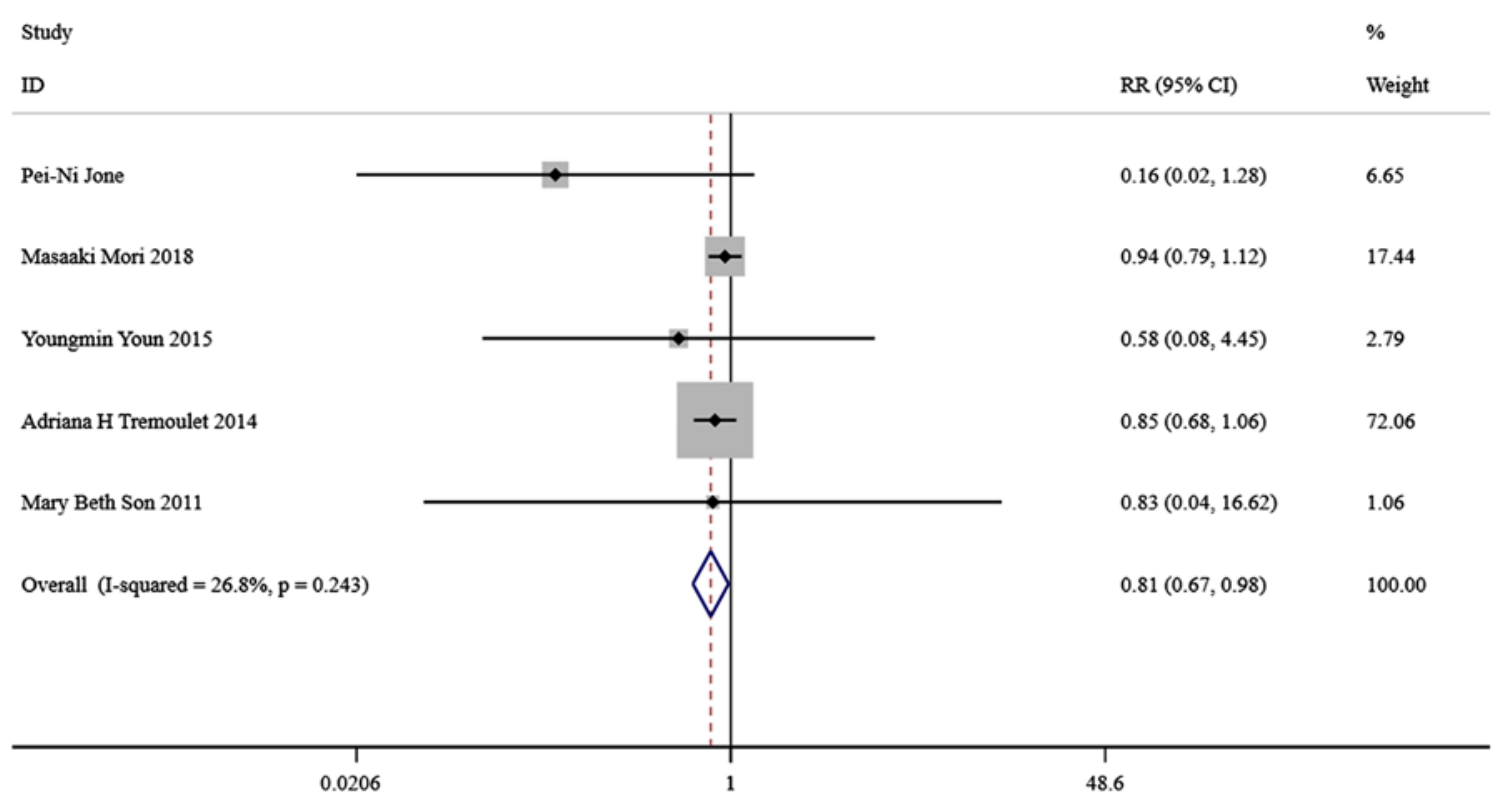

Figure 2. Forest plot for adverse events in IFX or IFX plus IVIG vs. IVIG or VGIH groups. IFX, infliximab; IVIG, intravenous immunoglobulin; VGIH, polyethylene glycol-treated human immunoglobulin; CI, confidence interval; RR, relative risk.

compared with that of the IVIG or VGIH groups. All the above results are presented in Figs. 2-4 and Table II.

Single-arm study. A total of seven studies containing 115 patients were included. The incidence of non-response rate $(0.083 ; 95 \% \mathrm{CI}: 0.028,0.138)$, adverse events $(0.156$; 95\% CI: 0.122, 0.190), fever (ES: 0.842; 95\% CI: 0.760, 0.924), conjunctival injection (ES: 0.618; 95\% CI: 0.509, 0.728), changes in lip and oral cavity (ES: $0.434 ; 95 \%$ CI: $0.323,0.546$ ), cervical lymphadenopathy (ES: 0.303 ; 95\% CI: 0.199, 0.406) and polymorphous exanthema (ES: 0.329 ; 95\% CI: 0.223 , $0.435)$ was significantly reduced after the IFX therapy. In addition, the WBC, neutrophil, ALT and CRP levels were reduced after the IFX therapy. The platelet count was significantly increased after the IFX therapy. No significant changes were observed in AST or ALT after the IFX therapy. After the IFX plus IVIG or IVMP therapy, the incidence of CAA was 0.150 (95\% CI: $0.024,0.277)$, and the non-response rate was 0.114 (95\% CI: $0.053,0.175)$. All the above results are presented in Figs. 5-7 and Table III.

Quality and bias assessment. Assessment of study quality and risk of bias was performed using multiple complementary methods including funnel plots, Begg's and Mazumdar's rank test, and Egger's test. Clear symmetry was observed in the log RR funnel plots for adverse events (Fig. 8) and non-response rate (Fig. 9) among the studies, suggesting a low publication bias risk. The results of Begg's and Mazumdar's rank test and Egger's test indicated no significant risk of bias among the study results (Tables II and III). 


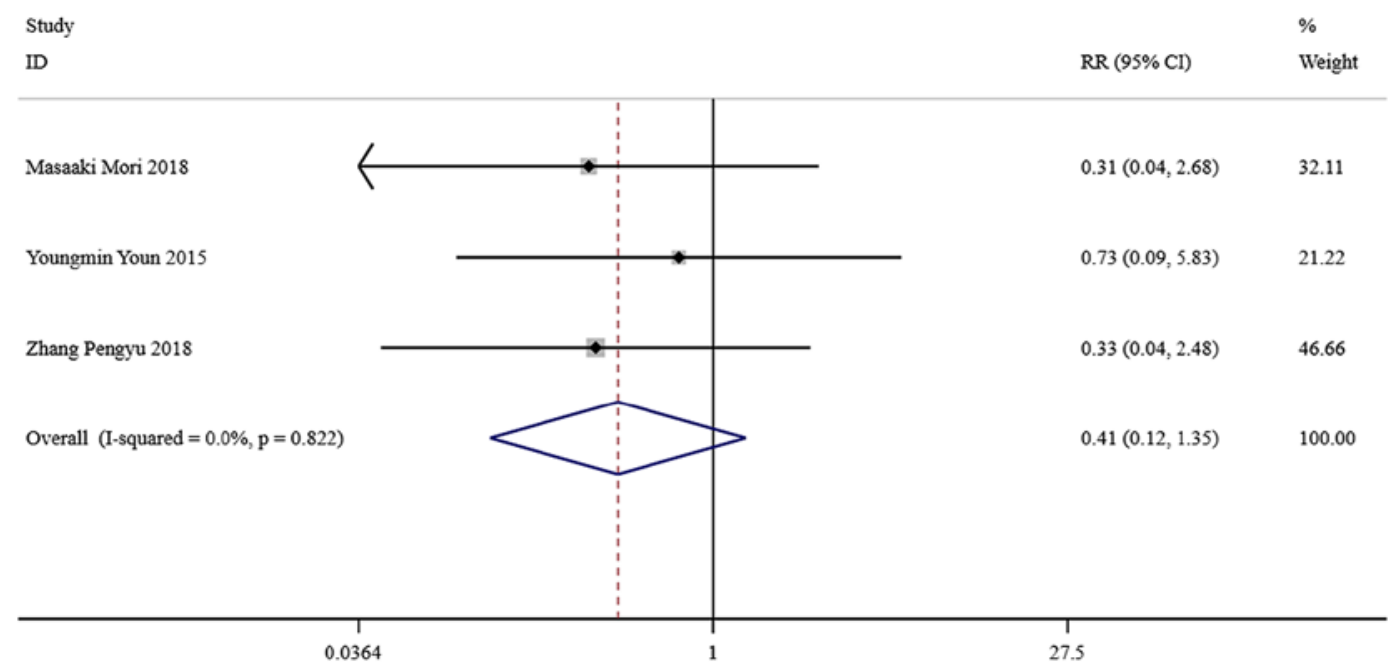

Figure 3. Forest plot for coronary artery damage of IFX or IFX plus IVIG vs. IVIG or VGIH groups. IFX, infliximab; IVIG, intravenous immunoglobulin; VGIH, polyethylene glycol-treated human immunoglobulin; CI, confidence interval; RR, relative risk.

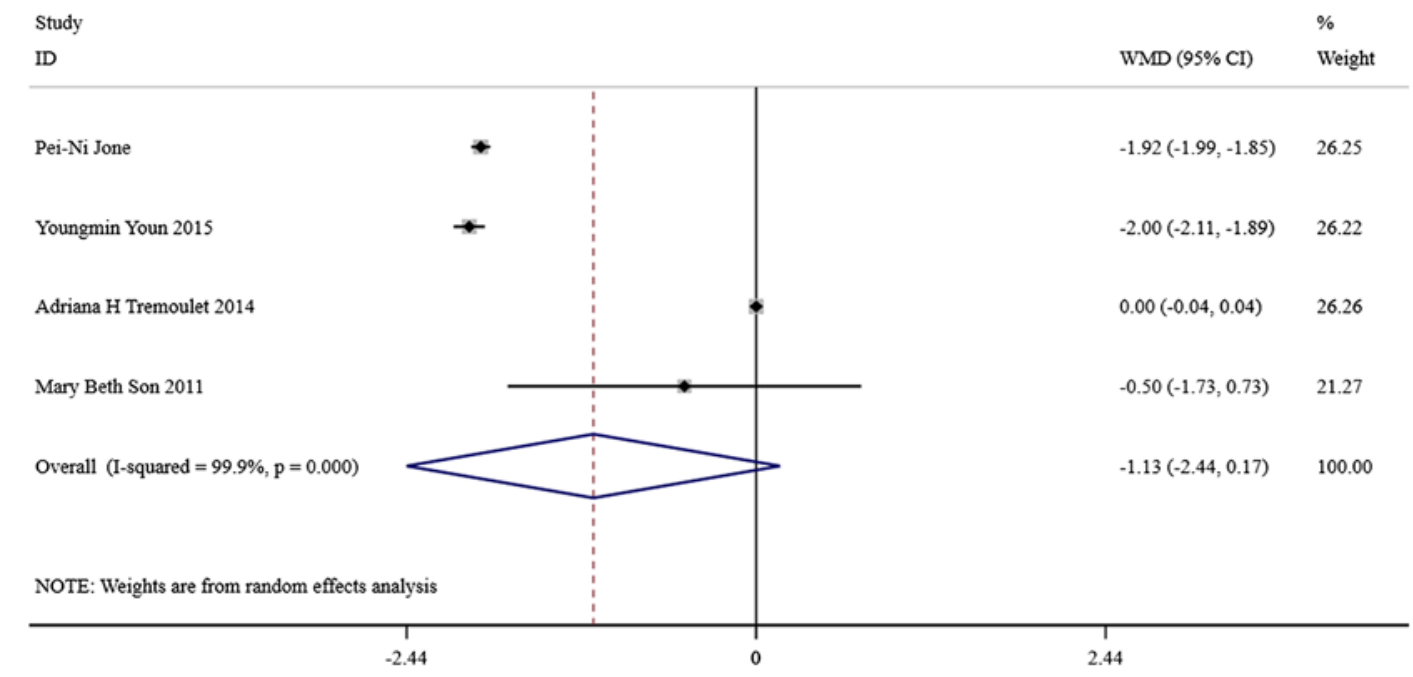

Figure 4. Forest plot for length of hospital stay of IFX or IFX plus IVIG vs. IVIG or VGIH groups. IFX, infliximab; IVIG, intravenous immunoglobulin; VGIH, polyethylene glycol-treated human immunoglobulin; CI, confidence interval; WMD, weighted mean difference.

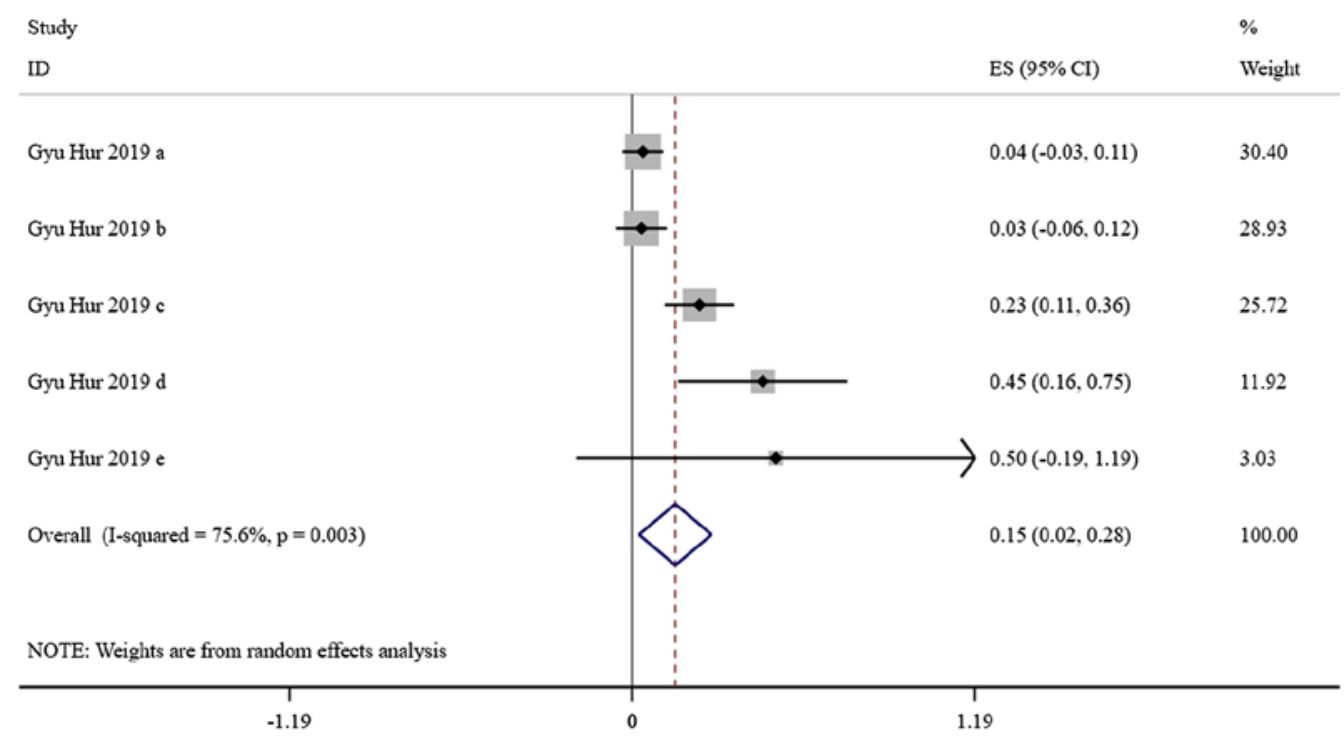

Figure 5. Forest plot for coronary artery aneurysm of the single-arm study. CI, confidence interval; ES, effect size. 
Table II. Results of case-control studies.

\begin{tabular}{|c|c|c|c|c|c|c|c|c|}
\hline \multirow[b]{2}{*}{ Index } & \multirow{2}{*}{$\begin{array}{l}\mathrm{N} \text { (case/ } \\
\text { control) }\end{array}$} & \multirow[b]{2}{*}{ Intervention } & \multirow[b]{2}{*}{ RR $(95 \% \mathrm{CI})$} & \multirow[b]{2}{*}{$\mathrm{P}^{\mathrm{a}}$} & \multirow[b]{2}{*}{$\mathrm{I}^{2}$} & \multirow[b]{2}{*}{$\mathrm{P}^{\mathrm{b}}$} & \multicolumn{2}{|c|}{ P-value } \\
\hline & & & & & & & Begg's & Egger's \\
\hline $\begin{array}{l}\text { Coronary } \\
\text { artery lesion }\end{array}$ & $49 / 113$ & $\begin{array}{l}\text { IFX vs. IVIG } \\
\text { or VGIH }\end{array}$ & $0.410(0.124,1.353)$ & 0.822 & $0.0 \%$ & 0.143 & $>0.009$ & 0.990 \\
\hline \multirow{3}{*}{$\begin{array}{l}\text { Coronary artery } \\
\text { aneurysm }\end{array}$} & $156 / 131$ & overall & $0.687(0.286,1.652)$ & 0.942 & $0.0 \%$ & 0.402 & $>0.009$ & - \\
\hline & $98 / 98$ & $\begin{array}{l}\text { IFX vs. IVIG } \\
\text { or VGIH }\end{array}$ & $0.667(0.194,2.289)$ & - & - & 0.520 & - & - \\
\hline & $58 / 53$ & $\begin{array}{l}\text { IFX plus IVIG vs. } \\
\text { IVIG or VGIH }\end{array}$ & $0.711(0.205,2.466)$ & - & - & 0.591 & - & - \\
\hline \multirow{2}{*}{$\begin{array}{l}\text { Non-response } \\
\text { rate }\end{array}$} & $144 / 164$ & overall & $0.466(0.165,1.315)$ & 0.082 & $60.1 \%$ & 0.149 & $>0.009$ & 0.577 \\
\hline & $\begin{array}{c}109 / 130 \\
35 / 34\end{array}$ & $\begin{array}{l}\text { IFX vs. IVIG or VGIH } \\
\text { IFX plus IVIG vs. } \\
\text { IVIG or VGIH }\end{array}$ & $\begin{array}{l}0.688(0.208,2.277) \\
0.259(0.096,0.702)\end{array}$ & $\begin{array}{c}0.201 \\
-\end{array}$ & $\begin{array}{c}38.7 \% \\
-\end{array}$ & $\begin{array}{l}0.540 \\
0.008\end{array}$ & $\begin{array}{c}>0.009 \\
-\end{array}$ & - \\
\hline Length of & $164 / 250$ & overall & $-1.135(-2.436,0.167)^{c}$ & 0.000 & $99.9 \%$ & 0.087 & $>0.009$ & 0.578 \\
\hline Hospital stay & $\begin{array}{c}129 / 216 \\
35 / 34\end{array}$ & $\begin{array}{l}\text { IFX vs. IVIG or VGIH } \\
\text { IFX plus IVIG vs. } \\
\text { IVIG or VGIH }\end{array}$ & $\begin{array}{l}-0.852(-2.492,0.787)^{\mathrm{c}} \\
-1.920(-1.986,-1.854)^{\mathrm{c}}\end{array}$ & $\begin{array}{c}0.000 \\
-\end{array}$ & $\begin{array}{c}99.8 \% \\
-\end{array}$ & $\begin{array}{r}0.308 \\
<0.001\end{array}$ & $\begin{array}{c}>0.009 \\
-\end{array}$ & $\begin{array}{c}0.661 \\
-\end{array}$ \\
\hline Adverse event & $\begin{array}{c}180 / 265 \\
145 / 231 \\
35 / 34\end{array}$ & $\begin{array}{c}\text { overall } \\
\text { IFX vs. IVIG or VGIH } \\
\text { IFX plus IVIG vs. } \\
\text { IVIG or VGIH }\end{array}$ & $\begin{array}{l}0.811(0.674,0.977) \\
0.858(0.715,1.029) \\
0.162(0.021,1.275)\end{array}$ & $\begin{array}{c}0.243 \\
0.736 \\
-\end{array}$ & $\begin{array}{c}26.8 \% \\
0.0 \% \\
-\end{array}$ & $\begin{array}{l}0.027 \\
0.099 \\
0.084\end{array}$ & $\begin{array}{c}0.806 \\
>0.009 \\
-\end{array}$ & $\begin{array}{l}0.193 \\
0.493 \\
-\end{array}$ \\
\hline Fever & $77 / 77$ & $\begin{array}{l}\text { IFX plus IVIG vs. } \\
\text { IVIG or VGIH }\end{array}$ & $1.706(1.287,2.261)$ & - & - & $<0.001$ & - & - \\
\hline $\begin{array}{l}\text { Conjunctival } \\
\text { injection }\end{array}$ & $77 / 77$ & $\begin{array}{l}\text { IFX plus IVIG vs. } \\
\text { IVIG or VGIH }\end{array}$ & $1.054(0.765,1.452)$ & - & - & 0.747 & - & - \\
\hline $\begin{array}{l}\text { Changes in lip } \\
\text { and oral cavity }\end{array}$ & $77 / 77$ & $\begin{array}{l}\text { IFX plus IVIG vs. } \\
\text { IVIG or VGIH }\end{array}$ & $1.452(1.043,2.021)$ & - & - & 0.027 & - & - \\
\hline $\begin{array}{l}\text { Cervical } \\
\text { lymphadenopathy }\end{array}$ & $77 / 77$ & $\begin{array}{l}\text { IFX plus IVIG vs. } \\
\text { IVIG or VGIH }\end{array}$ & $1.586(1.128,2.23)$ & - & - & 0.008 & - & - \\
\hline $\begin{array}{l}\text { Polymorphous } \\
\text { exanthema }\end{array}$ & $77 / 77$ & $\begin{array}{l}\text { IFX plus IVIG vs. } \\
\text { IVIG or VGIH }\end{array}$ & $1.040(0.664,1.629)$ & - & - & 0.864 & - & - \\
\hline Z-score & $93 / 67$ & $\begin{array}{l}\text { IFX plus IVIG vs. } \\
\text { IVIG or VGIH }\end{array}$ & $0.165(0.038,0.292)^{\mathrm{c}}$ & 0.000 & $93.2 \%$ & 0.011 & $>0.009$ & - \\
\hline $\begin{array}{l}\text { WBC count, } \\
10^{3} / \mathrm{mm}^{3}\end{array}$ & $98 / 98$ & IFX vs. IVIG or VGIH & $-0.060(-0.071,-0.049)^{\mathrm{c}}$ & - & - & $<0.001$ & - & - \\
\hline $\begin{array}{l}\text { Neutrophil } \\
\text { count, } 10^{3} / \mathrm{mm}^{3}\end{array}$ & $98 / 98$ & IFX vs. IVIG or VGIH & $-1.160(-1.171,-1.149)^{\mathrm{c}}$ & - & - & $<0.001$ & - & - \\
\hline $\begin{array}{l}\text { Platelet count, } \\
10^{4} / 1\end{array}$ & $98 / 98$ & IFX vs. IVIG or VGIH & $10.040(9.803,10.277)^{\mathrm{c}}$ & - & - & $<0.001$ & - & - \\
\hline ALT, IU/1 & $98 / 98$ & IFX vs. IVIG or VGIH & $1.200(1.162,1.238)^{\mathrm{c}}$ & - & - & $<0.001$ & - & - \\
\hline $\mathrm{CRP}, \mathrm{mg} / \mathrm{dl}$ & $120 / 130$ & IFX vs. IVIG or VGIH & $-3.000(-3.017,-2.983)^{\mathrm{c}}$ & 0.592 & $0.0 \%$ & $<0.001$ & $>0.009$ & 0.992 \\
\hline
\end{tabular}

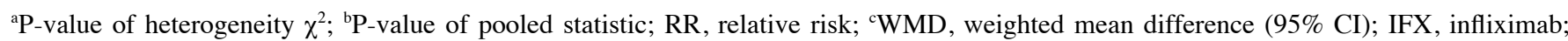
IVIG, intravenous immunoglobulin; VGIH, polyethylene glycol-treated human immunoglobulin; IVMP, intravenous methyl prednisolone; WBC, white blood cell; ALT, alanine transaminase; CRP, C-reactive protein. -: when only one paper is included, the numerical value cannot be calculated, so it is blank.

\section{Discussion}

The main pathological change of KD is systemic vasculitis, and its pathogenesis is associated with autoimmune abnormalities. The main worst complication of KD is CAL, and a number of patients also develop giant tubular aneurysms, which may lead to thrombosis and rupture bleeding $(30,31)$. IVIG is isolated and purified from healthy human plasma and 


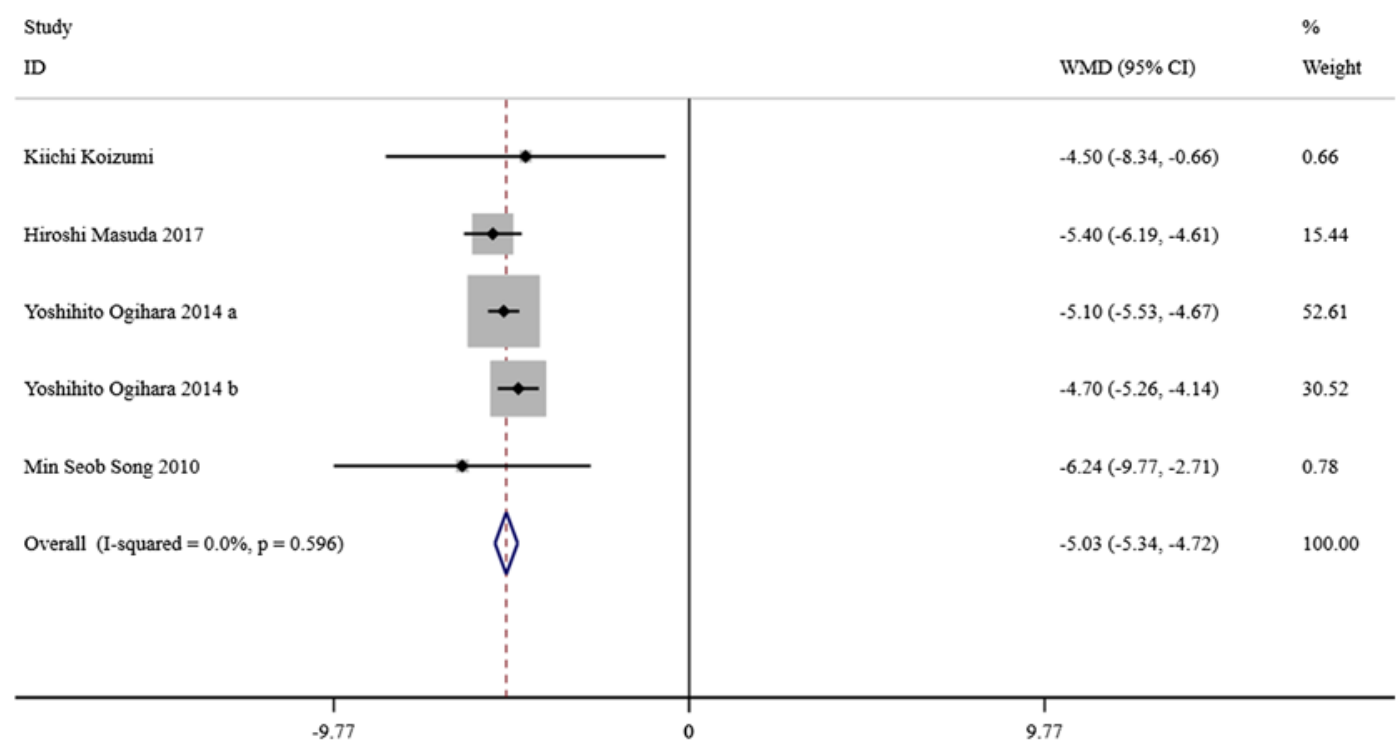

Figure 6. Forest plot for C-reactive protein of the single-arm study. CI, confidence interval; WMD, weighted mean difference.

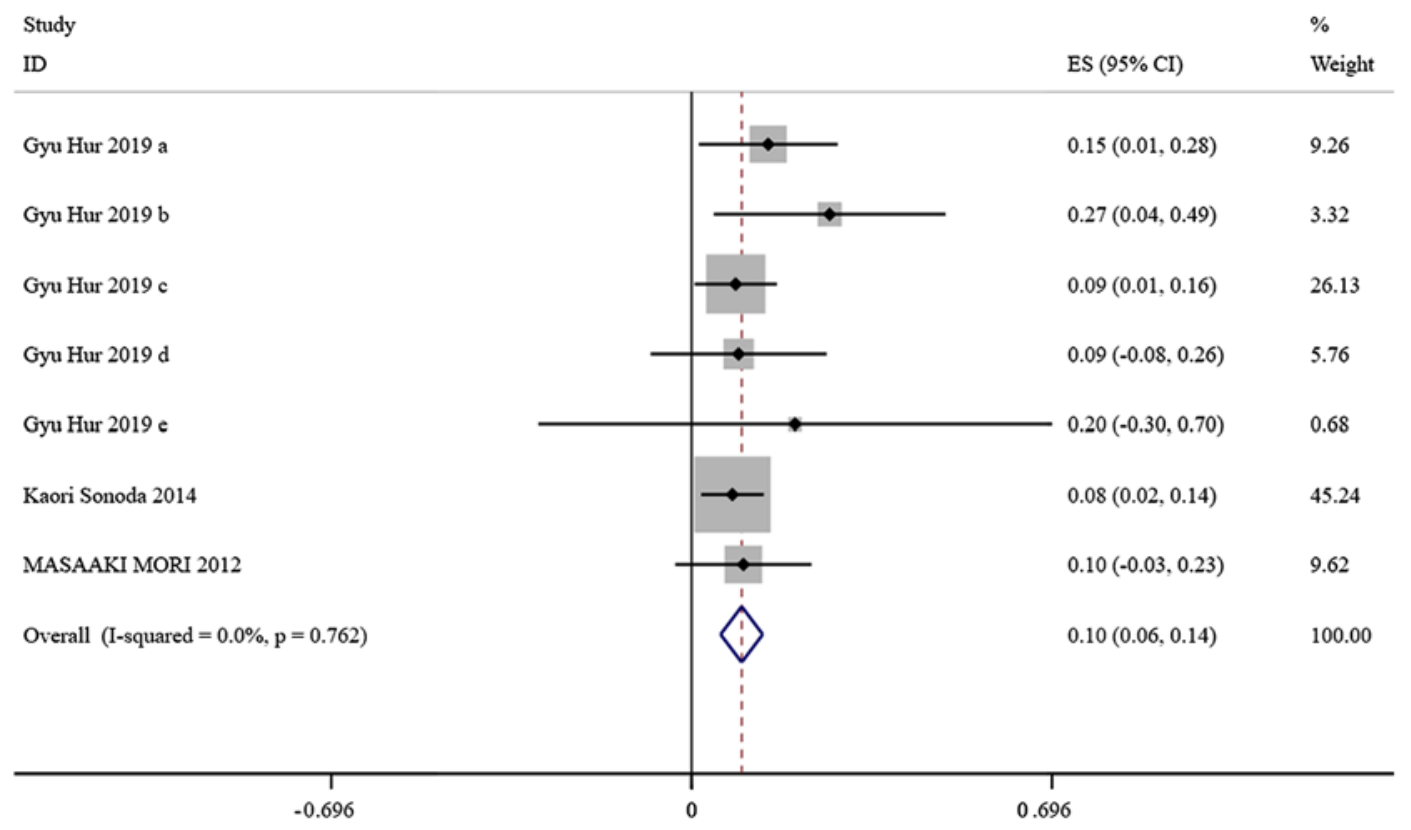

Figure 7. Forest plot for non-response rate of the single-arm study. CI, confidence interval; ES, effect size.

has been initially used as a replacement therapy for treating children with primary and secondary immunodeficiency or autoimmune and inflammatory diseases (32-34). IVIG therapy may benefit children with KD through the following potential mechanisms (35): i) Inhibiting the activation of innate immune cells such as dendritic cells, macrophages, monocytes, neutrophils, and secretion of inflammatory mediators; ii) regulating $\mathrm{B}$ cell responses and reducing the production of autoantibodies; iii) inhibiting pathogenic T helper (Th) 1 and Th17 cells and endothelial cell activation; and iv) enhancing regulatory T lymphocyte levels. Although none of these mechanisms could fully explain the pathogenesis of KD, some have been demonstrated to be feasible in children with KD (36). The efficacy of IVIG in preventing CAL can be confirmed (37). As a blood product, IVIG has a number of limitations such as limited sources, a high price and the potential risk of infection. In addition, the incidence rate of non-responders to IVIG can reach as high as $10 \%$ (38). Thus, scientists are actively looking for other treatments to achieve better and faster clinical symptom relief and reduce the incidence of CAL.

In the acute phase of KD, the plasma TNF- $\alpha$ level is significantly increased, and the plasma TNF- $\alpha$ level in children with CAD is higher compared with those without CAD. TNF- $\alpha$ can directly induce vascular endothelial cells to express intercellular adhesion molecule-1 and monocyte chemokine-1, thus promoting the infiltration of neutrophils, monocytes and other inflammatory cells to aggravate the inflammatory injury of blood vessels. IFX is a human and mouse chimeric monoclonal antibody that specifically blocks TNF- $\alpha$ with high affinity and inhibits the binding of 
Table III. Results of single-arm studies.

\begin{tabular}{|c|c|c|c|c|c|c|c|c|}
\hline \multirow[b]{2}{*}{ Index } & \multirow[b]{2}{*}{$\mathrm{N}$} & \multirow[b]{2}{*}{ Intervention } & \multirow[b]{2}{*}{$\mathrm{ES}(95 \% \mathrm{CI})$} & \multirow[b]{2}{*}{$\mathrm{P}^{\mathrm{a}}$} & \multirow[b]{2}{*}{$\mathrm{I}^{2}$} & \multirow[b]{2}{*}{$\mathrm{P}^{\mathrm{b}}$} & \multicolumn{2}{|c|}{ P-value } \\
\hline & & & & & & & Begg's & Egger's \\
\hline Coronary artery aneurysm & 102 & $\begin{array}{l}\text { IFX plus IVIG } \\
\text { or IVMP }\end{array}$ & $0.150(0.024,0.277)$ & 0.003 & $75.6 \%$ & 0.020 & $>0.009$ & - \\
\hline \multirow[t]{3}{*}{ Non-response rate } & 198 & overall & $0.097(0.056,0.138)$ & 0.762 & $0.0 \%$ & $<0.001$ & $>0.009$ & 0.854 \\
\hline & 96 & IFX & $0.083(0.028,0.138)$ & 0.776 & $0.0 \%$ & 0.003 & - & - \\
\hline & 102 & $\begin{array}{l}\text { IFX plus IVIG } \\
\text { or IVMP }\end{array}$ & $0.114(0.053,0.175)$ & 0.604 & $0.0 \%$ & $<0.001$ & 0.117 & 0.031 \\
\hline Adverse event & 443 & IFX & $0.156(0.122,0.190)$ & - & - & $<0.001$ & - & - \\
\hline Fever & 76 & IFX & $0.842(0.760,0.924)$ & - & - & $<0.001$ & - & - \\
\hline Conjunctival injection & 76 & IFX & $0.618(0.509,0.728)$ & - & - & $<0.001$ & - & - \\
\hline Changes in lip and oral cavity & 76 & IFX & $0.434(0.323,0.546)$ & - & - & $<0.001$ & - & - \\
\hline Cervical lymphadenopathy & 76 & IFX & $0.303(0.199,0.406)$ & - & - & $<0.001$ & - & - \\
\hline Polymorphous exanthema & 76 & IFX & $0.329(0.223,0.435)$ & - & - & $<0.001$ & - & - \\
\hline WBC count, $10^{3} / \mathrm{mm}^{3}$ & 473 & IFX & $-4.011(-5.485,-2.536)^{\mathrm{c}}$ & 0.000 & $87.2 \%$ & $<0.001$ & $>0.009$ & 0.629 \\
\hline Neutrophil count, $10^{3} / \mathrm{mm}^{3}$ & 30 & IFX & $-4.771(-5.675,-3.867)^{\mathrm{c}}$ & 0.001 & $84.8 \%$ & $<0.001$ & $>0.009$ & 0.914 \\
\hline Platelet count, $10^{4} / \mu 1$ & 460 & IFX & $11.568(10.440,12.697)^{\mathrm{c}}$ & 0.768 & $0.0 \%$ & $<0.001$ & $>0.009$ & 0.479 \\
\hline AST, IU/1 & 460 & IFX & $1.271(-1.729,4.271)^{\mathrm{c}}$ & 0.000 & $87.8 \%$ & 0.406 & $>0.009$ & 0.780 \\
\hline ALT, IU/1 & 460 & IFX & $-1.416(-5.339,2.507)^{\mathrm{c}}$ & 0.005 & $81.2 \%$ & 0.479 & 0.296 & 0.370 \\
\hline $\mathrm{CRP}, \mathrm{mg} / \mathrm{dl}$ & 489 & IFX & $-5.029(-5.341,-4.718)^{\mathrm{c}}$ & 0.596 & $0.0 \%$ & $<0.001$ & $>0.009$ & 0.703 \\
\hline
\end{tabular}

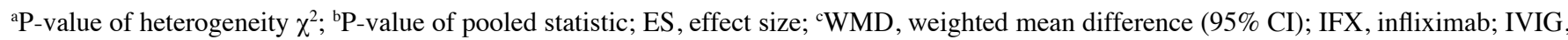
intravenous immunoglobulin; VGIH, polyethylene glycol-treated human immunoglobulin; IVMP, intravenous methyl prednisolone; WBC, white blood cell; AST, aspartate aminotransferase; ALT, alanine transaminase; CRP, C-reactive protein. -: when only one paper is included, the numerical value cannot be calculated, so it is blank.

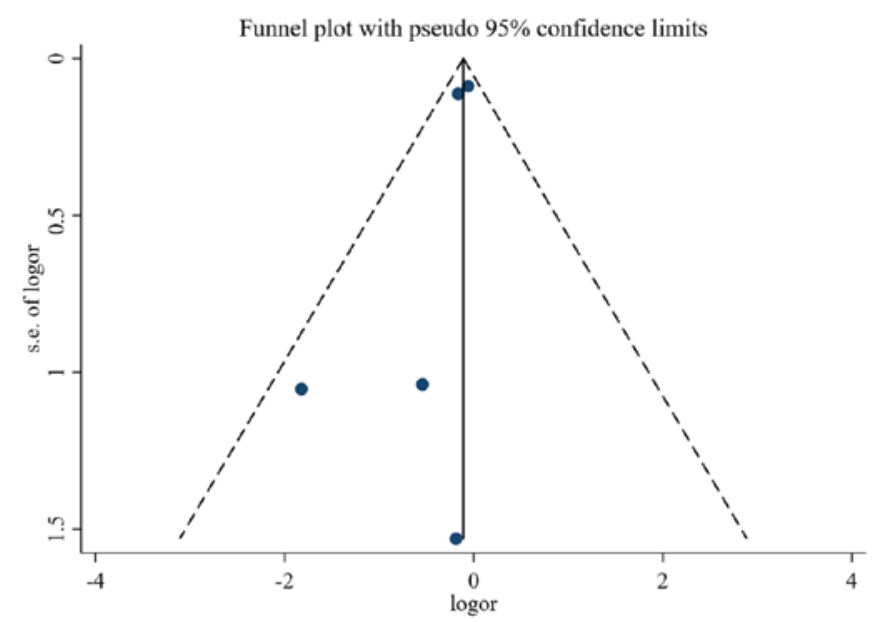

Figure 8. Log RR funnel plot analysis of the included studies of IFX or IFX plus IVIG vs. IVIG or VGIH groups. IFX, infliximab; IVIG, intravenous immunoglobulin; VGIH, polyethylene glycol-treated human immunoglobulin.

TNF- $\alpha$ to its receptor. Currently, IFX is mainly used for the treatment of rheumatoid arthritis, ankylosing spondylitis, psoriatic arthritis and Crohn's disease. Specific blocking of TNF- $\alpha$ has been demonstrated to prevent coronary inflammation and the formation of CAA in mouse KD models induced by Lactobacillus casei cell wall extracts. In a previous study of a KD model in mice, it was indicated

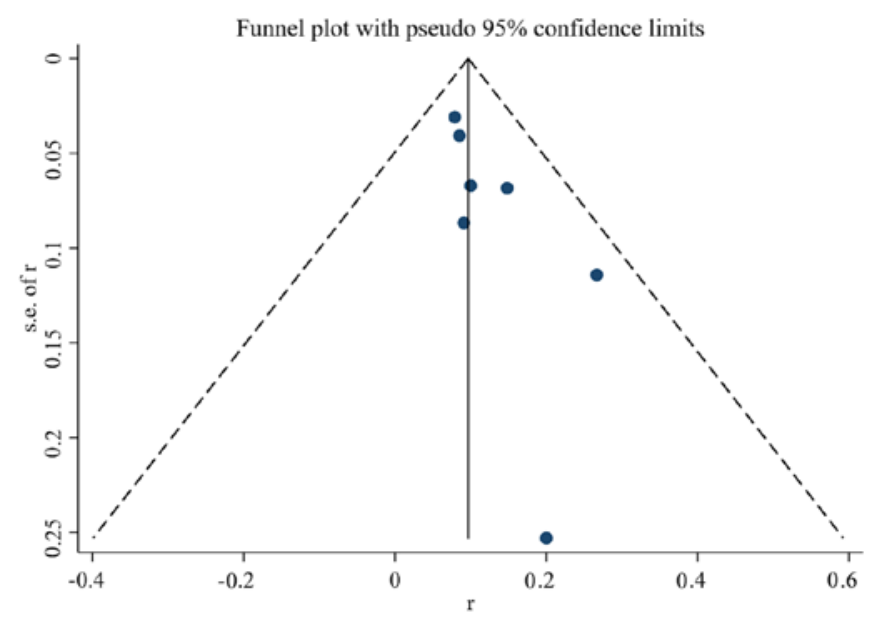

Figure 9. $\log$ RR funnel plot analysis of the included studies of the single-arm analysis.

that a TNF- $\alpha$ anticoagulant can reduce the adhesion of neutrophils to vascular endothelial cells and the inflammation of arterial vascular endothelial cells (24,39-42). In the present meta-analysis, no significant differences in CAL, CAA, non-response rate, length of hospital stay, conjunctival injection or polymorphous exanthema between the two groups were observed; however, IFX or IFX plus IVIG significantly reduced the incidence of adverse events, the 
number of patients with fever, changes in lip and oral cavity and cervical lymphadenopathy. The WBC, neutrophil and CRP levels were also reduced in the IFX or IFX plus IVIG groups compared with those in the IVIG or VGIH groups. In addition, the platelet and ALT levels, as well as the Z-score were increased in the IFX or IFX plus IVIG groups compared with those in the IVIG or VGIH groups. Thus, IFX or IFX plus IVIG exhibited improved clinical efficacy in the treatment of KD compared with that of IVIG or VGIH.

In the single-arm studies, IFX would decrease the incidence of CAA, the non-response rate and the incidence of adverse events. IFX demonstrated a high efficacy in reducing the incidence of fever, conjunctival injection, changes in lip and oral cavity, cervical lymphadenopathy, polymorphous exanthema, as well as WBC, neutrophil, ALT and CRP levels. In addition, the platelet count was significantly increased after the IFX therapy. However, as only a limited number of studies were included in the current meta-analysis, the clinical efficacy of IFX in the treatment of KD should be further verified.

In a similar meta-analysis, Yamaji et al (42) evaluated the efficacy and safety of using TNF- $\alpha$ blockers (i.e. IFX and etanercept) to treat children with KD. Low-certainty evidence from five trials indicated that TNF- $\alpha$ blockers exhibited positive effects on treatment resistance and the infusion reaction after treatment initiation for KD compared with non-treatment or additional treatment with IVIG. However, further large-scaled high-quality trials including the timing and type of TNF- $\alpha$ blockers are needed to determine the effects of TNF- $\alpha$ blockers for KD. In the study of Yamaji et al (42), TNF- $\alpha$ blockers reduced the incidence of treatment resistance and infusion reaction, but no clear difference was observed between groups in the incidence of CAAs, rash or contact dermatitis. The conclusions about CAA is consistent with the present analysis.

The systematic nature of the present meta-analysis allowed the results to be more convincing compared with those of individual studies, since these results relied upon a large pooled sample size, which was one of the strengths of the current meta-analysis. In addition, strict inclusion and exclusion criteria were used to select the qualified studies, and all the data were analyzed by standard statistical analyses to ensure accuracy, thus allowing the conclusion to be clinically significant.

However, there were certain limitations to the present analysis. For example, the therapy course and the combination of drugs, as well as the severity of KD and combined disease lacked conformity, and each study had variations in the exclusion/inclusion criteria. Furthermore, a limited number of studies was included, and as individual patient data were not available, only pooled data were analyzed, thus precluding more in-depth analyses.

In conclusion, IFX or IFX plus IVIG exhibited improved clinical efficacy in the treatment of KD compared with that of IVIG or VGIH.

\section{Acknowledgements}

Not applicable.

\section{Funding}

No funding was received.

\section{Availability of data and materials}

The datasets used and/or analyzed during the current study are available from the corresponding author on reasonable request.

\section{Authors' contributions}

ZL and FW conceived and designed the study. HL, ZL and FW acquired, analyzed and interpreted the data. All authors read and approved the final manuscript.

\section{Ethics approval and consent to participate}

Not applicable.

\section{Patient consent for publication}

Not applicable.

\section{Competing interests}

The authors declare that they have no competing interests.

\section{References}

1. Kawasaki T: Acute febrile mucocutaneous syndrome with lymphoid involvement with specific desquamation of the fingers and toes in children. Arerugi 16: 178-222, 1967 (In Japanese).

2. Miura M, Tamame T, Naganuma T, Chinen S, Matsuoka M and Ohki H: Steroid pulse therapy for Kawasaki disease unresponsive to additional immunoglobulin therapy. Paediatr Child Health 16: 479-484, 2011.

3. Soriano-Ramos M, Martínez-Del Val E, Negreira Cepeda S, González-Tomé MI, Cedena Romero P, Fernández-Cooke E, Albert de la Torre L and Blázquez-Gamero D: Risk of coronary artery involvement in Kawasaki disease. Arch Argent Pediatr 114: 107-113, 2016 (In English, Spanish).

4. Koizumi K, Hoshiai M, Katsumata N, Toda T, Kise H, Hasebe Y, Kono Y, Sunaga Y, Yoshizawa M, Watanabe A, et al: Infliximab regulates monocytes and regulatory $\mathrm{T}$ cells in Kawasaki disease. Pediatr Int 60: 796-802, 2018.

5. Lin Y, Xiao-hui L and Shi L: Interpretation of the 2017 edition of diagnosis, treatment, and long-term management of Kawasaki disease: A scientific statement for health professionals from the American heart association. Chin J Pract Pediatr, 2017 (In Chinese).

6. Makino N, Nakamura Y, Yashiro M, Sano T, Ae R, Kosami K, Kojo T, Aoyama Y, Kotani K and Yanagawa H: Epidemiological observations of Kawasaki disease in Japan, 2013-2014. Pediatr Int 60: 581-587, 2018.

7. Newburger JW, Takahashi M, Gerber MA, Gewitz MH Tani LY, Burns JC, Shulman ST, Bolger AF, Ferrieri P, Baltimore RS, et al: Diagnosis, treatment, and long-term management of Kawasaki disease: A statement for health professionals from the committee on rheumatic fever, endocarditis, and Kawasaki disease, council on cardiovascular disease in the young, American heart association. Pediatrics 114: 1708-1733, 2004.

8. Lee Y, Schulte DJ, Shimada K, Chen S, Crother TR, Chiba N, Fishbein MC, Lehman TJ and Arditi M: Interleukin- $1 \beta$ is crucial for the induction of coronary artery inflammation in a mouse model of Kawasaki disease. Circulation 125: 1542-1550, 2012.

9. Newburger JW, Takahashi M, Beiser AS, Burns JC, Bastian J, Chung KJ, Colan SD, Duffy CE, Fulton DR, Glode MP, et al: A single intravenous infusion of gamma globulin as compared with four infusions in the treatment of acute Kawasaki syndrome. N Engl J Med 324: 1633-1639, 1991. 
10. Furukawa T, Kishiro M, Akimoto K, Nagata S, Shimizu T and Yamashiro Y: Effects of steroid pulse therapy on immunoglobulin-resistant Kawasaki disease. Arch Dis Child 93: 142-146, 2008.

11. Matsubara T, Ichiyama T and Furukawa S: Immunological profile of peripheral blood lymphocytes and monocytes/macrophages in Kawasaki disease. Clin Exp Immunol 141: 381-387, 2005

12. Research Committee of the Japanese Society of Pediatric Cardiology; Cardiac Surgery Committee for Development of Guidelines for Medical Treatment of Acute Kawasaki Disease: Guidelines for medical treatment of acute Kawasaki disease: Report of the research committee of the Japanese society of pediatric cardiology and cardiac surgery (2012 revised version). Pediatr Int 56: 135-158, 2014

13. Ogihara Y, Ogata S, Nomoto K, Ebato T, Sato K, Kokubo K, Kobayashi $\mathrm{H}$ and Ishii $\mathrm{M}$ : Transcriptional regulation by infliximab therapy in Kawasaki disease patients with immunoglobulin resistance. Pediatr Res 76: 287-293, 2014.

14. Saji BT and Kobayashi T: Overview of the new Japanese guideline2012 for the medical treatment of acute stage of Kawasaki disease. In: Kawasaki Disease. Saji B, Newburger J, Burns J, and Takahashi M (eds). Springer, Tokyo, pp103-167, 2017.

15. Xiantao Zeng, Zhu Sun, Tang. H. No. 10 of the Meta Analysis Series: Formulation of Eligibility Criteria. Chin J Evid Based Cardiovasc Med 5: e927-e999, 2013.

16. Hirono K, Kemmotsu Y, Wittkowski H, Foell D, Saito K, Ibuki K, Watanabe K, Watanabe S, Uese K, Kanegane H, et al: Infliximab reduces the cytokine-mediated inflammation but does not suppress cellular infiltration of the vessel wall in refractory Kawasaki disease. Pediatr Res 65: 696-701, 2009.

17. Jone PN, Anderson MS, Mulvahill MJ, Heizer H, Glodé MP and Dominguez SR: Infliximab plus intravenous immunoglobulin (IVIG) versus IVIG alone as initial therapy in children with kawasaki disease presenting with coronary artery lesions: Is dual therapy more effective? Pediatr Infect Dis J 37: 976-980, 2018.

18. Mori M,Hara T,Kikuchi M,Shimizu H, Miyamoto T, Iwashima S, Oonishi T, Hashimoto K, Kobayashi N, Waki K, et al: Infliximab versus intravenous immunoglobulin for refractory Kawasaki disease: A phase 3, randomized, open-label, active-controlled, parallel-group, multicenter trial. Sci Rep 8: 1994, 2018.

19. Zhang P, Tang C, Pan X, Chi H, Sun W and Qu S: Comparison of the effects of infliximab and IVIG in the treatment of ineffective IVIG. China Med Front Magazine (electronic version) 10: 66-69, 2018.

20. Son MB, Gauvreau K, Burns JC, Corinaldesi E, Tremoulet AH, Watson VE, Baker A, Fulton DR, Sundel RP and Newburger JW: Infliximab for intravenous immunoglobulin resistance in kawasaki disease: A retrospective study. J Pediatr 158: 644-649.el, 2011.

21. Sonoda K, Mori M, Hokosaki T and Yokota S: Infliximab plus plasma exchange rescue therapy in Kawasaki disease. J Pediatr 164: 1128-1132.e1, 2014.

22. Tremoulet AH, Jain S, Jaggi P, Jimenez-Fernandez S, Pancheri JM Sun X, Kanegaye JT, Kovalchin JP, Printz BF, Ramilo O and Burns JC: Infliximab for intensification of primary therapy for Kawasaki disease: A phase 3 randomised, double-blind, placebo-controlled trial. Lancet 383: 1731-1738, 2014.

23. Youn Y, Kim J, Hong YM and Sohn S: Infliximab as the first retreatment in patients with Kawasaki disease resistant to initial intravenous immunoglobulin. Pediatr Infect Dis J 35: 457-459, 2016

24. Hur G, Song MS, Sohn S, Lee HD, Kim GB, Cho HJ, Yoon KL, Joo CU, Hyun MC and Kim CH: Infliximab treatment for intravenous immunoglobulin-resistant Kawasaki disease: A multicenter study in Korea. Korean Circ J 49: 183-191, 2019.

25. Dionne A, Burns JC, Dahdah N, Tremoulet AH, Gauvreau K, de Ferranti SD, Baker AL, Son MB, Gould P, Fournier A, et al: Treatment intensification in patients with Kawasaki disease and coronary aneurysm at diagnosis. Pediatrics 143: pii: e20183341, 2019.

26. Mori M, Imagawa T, Hara R, Kikuchi M, Hara T, Nozawa T, Miyamae T and Yokota S: Efficacy and limitation of infliximab treatment for children with Kawasaki disease intractable to intravenous immunoglobulin therapy: Report of an open-label case series. J Rheumatol 39: 864-867, 2012.
27. Han CL and Zhao SL: Intravenous immunoglobulin gamma (IVIG) versus IVIG plus infliximab in young children with Kawasaki disease. Med Sci Monit 24: 7264-7270, 2018.

28. Masuda H, Kobayashi T, Hachiya A, Nakashima Y, Shimizu H, Nozawa T, Ogihara Y, Ito S, Takatsuki S, Katsumata N, et al: Infliximab for the treatment of refractory Kawasaki disease: A nationwide survey in Japan. J Pediatr 195: 115-120.e3, 2018.

29. Song MS, Lee SB, Sohn S, Oh JH, Yoon KL, Han JW and $\mathrm{Kim} \mathrm{CH}$ : Infliximab treatment for refractory kawasaki disease in korean children. Korean Circ J 40: 334-338, 2010.

30. Burns JC, Song Y, Bujold M, Shimizu C, Kanegaye JT, Tremoulet $\mathrm{AH}$ and Franco A: Immune-monitoring in Kawasaki disease patients treated with infliximab and intravenous immunoglobulin. Clin Exp Immunol 174: 337-344, 2013.

31. Galeotti C, Kaveri SV, Cimaz R, Koné-Paut I and Bayry J: Predisposing factors, pathogenesis and therapeutic intervention of Kawasaki disease. Drug Discov Today 21: 1850-1857, 2016.

32. Moffett BS, Syblik D, Denfield S, Altman C and Tejtel-Sexson K: Epidemiology of immunoglobulin resistant Kawasaki disease: Results from a large, national database. Pediatr Cardiol 36: 374-378, 2015.

33. Furusho K, Kamiya T, Nakano H, Kiyosawa N, Shinomiya K, Hayashidera T, Tamura T, Hirose O, Manabe Y, Yokoyama T, et al: High-dose intravenous gammaglobulin for Kawasaki disease. Lancet 2: 1055-1058, 1984.

34. Rasouli M, Heidari B and Kalani M: Downregulation of Th17 cells and the related cytokines with treatment in Kawasaki disease. Immunol Lett 162: 269-275, 2014

35. Guo MH, Tseng WN, Ko CH, Pan HM, Hsieh KS and Kuo HC: Th17- and Treg-related cytokine and mRNA expression are associated with acute and resolving Kawasaki disease. Allergy 70: 310-318, 2015.

36. Bai X, Zhang R and Zhong J: Prediction of unresponsiveness to intravenous immunoglobulin retreatmentin patients with Kawasaki disease. Chin J Evid Based Pediatr 11: 16-20, 2016 (In Cbinese).

37. Burns JC, Capparelli EV, Brown JA, Newburger JW and Glode MP: Intravenous gamma-globulin treatment and retreatment in Kawasaki disease. US/Canadian Kawasaki syndrome study group. Pediatr Infect Dis J 17: 1144-1148, 1998.

38. Newburger JW, Takahashi M, Gerber MA, Gewitz MH, Tani LY, Burns JC, Shulman ST, Bolger AF, Ferrieri P, Baltimore RS, et al: Diagnosis, treatment, and long-term management of Kawasaki disease: A statement for health professionals from the committee on rheumatic fever, endocarditis and Kawasaki disease, council on cardiovascular disease in the young, American heart association. Circulation 110: 2747-2771,2004.

39. Matsubara T, Furukawa S and Yabuta K: Serum levels of tumor necrosis factor, interleukin 2 receptor, and interferon-gamma in Kawasaki disease involved coronary-artery lesions. Clin Immunol Immunopathol 56: 29-36, 1990.

40. Ahn SY, Jang GC, Shin JS, Shin KM and Kim DS: Tumor necrosis factor-alpha levels and promoter polymorphism in patients with Kawasaki disease in Korea. Yonsei Med J 44: 1021-1026, 2003.

41. Hui-Yuen JS, Duong TT and Yeung RS: TNF-alpha is necessary for induction of coronary artery inflammation and aneurysm formation in an animal model of Kawasaki disease. J Immunol 176: 6294-6301, 2006.

42. Yamaji N, da Silva Lopes K, Shoda T, Ishitsuka K, Kobayashi T, Ota E and Mori R: TNF- $\alpha$ blockers for the treatment of Kawasaki disease in children. Cochrane Database Syst Rev 8: CD012448, 2019.

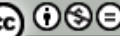

This work is licensed under a Creative Commons Attribution-NonCommercial-NoDerivatives 4.0 International (CC BY-NC-ND 4.0) License. 